Hamilton, M. A. (1960) Rating scale for depression. Journal of Neurology, Neurosurgery and Psychiatry, 23, 56-61.

National Institute for Health and Clinical Excellence (2009) Depression: The Treatment and Management of Depression in Adults (Update) (CG90). Available at http://www.nice.org.uk/CG90 (accessed 4 February 2013).

Neumeister, A., Praschak-Rieder, N. Besselmann, B et al (1997) Effects of tryptophan depletion on drug-free patients with seasona affective disorder during a stable response to bright light therapy. Archives of General Psychiatry, 54, 133-138.
Rethorst, C. D., Wipfli, B. M. \& Landers, D. M. (2009) The antidepressive effects of exercise: a meta-analysis of randomized trials. Sports Medicine, 39, 491-511.

Singh, G., Kaur, D. \& Kaur, H. (1984) Presumptive Stressful Life Events Scale (PSLES) - a new stressful life events scale for use in India. Indian Journal of Psychiatry, 26, 107-114.

Whaley, M. H., Brubaker, P. H., Otto, R. M., et al (2006) ACSM's Guidelines for Exercise Testing and Prescription (7th edn). Lippincott, Williams \& Wilkins.

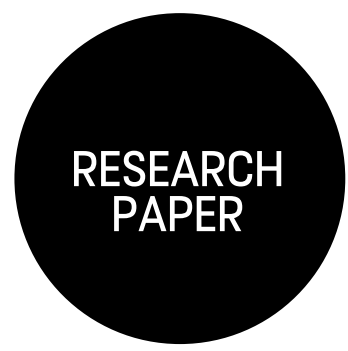

\title{
Scaling up mental healthcare in the Republic of Niger: priorities for and barriers to service improvement
}

\author{
Alison Hwong, ${ }^{1}$ Djibo Maiga Douma, ${ }^{2}$ Soumana Zamo ${ }^{3}$ and Julian Eaton ${ }^{4}$
}

${ }^{1} \mathrm{MD}-\mathrm{PhD}$ Candidate, Harvard Medical School, Boston, MA USA, email Alison_Hwong@hms. harvard.edu

${ }^{2}$ Psychiatrist and Assistant Professor, National Programme in Mental Health, Ministry of Public Health, Niger: Faculty of Health Sciences, Abdou Moun University, Niamey, Niger ${ }^{3}$ Country Representative, CBM Niger Country Coordination Office, Niamey, Niger

${ }_{4}^{4}$ Global Mental Health Advisor, CBM West Africa Regional Office, Lomé, Togo

The authors thank Salifou Badage of the National Menta Health Programme in Niger for is assistance with the in ast Kerim Munir for support and guidance

The CBM International and the Office of Enrichment Programs at Harvard Medical School funded the study
As part of a pilot programme to scale up community mental health services, local health centre directors, community health workers and key informants were interviewed in two neighbouring political districts of Niger. Major priorities for improving services included training staff on the diagnosis and treatment of mental illness, collaborating with traditional healers, educating the community about the origins of psychiatric illness and building infrastructure for medication delivery. Barriers to care included long distances for travel to the nearest hospital and lack of funding for homebased visits by health workers. This study was the first step in Niger's plan to implement the World Health Organization's Mental Health Gap Action Programme (mhGAP) at a national level.

Mental health remains one of the most neglected areas in healthcare in sub-Saharan Africa (World Health Organization, 2011), where the focus of health and development programmes has been on malaria, HIV/AIDS, maternal and child health and malnutrition. Current mental health system reform in Niger plans to use the World Health Organization's Mental Health Gap Action Programme (mhGAP) as a guide to scale up mental health services by integrating them with primary care, employing general healthcare staff in a process of task-shifting (World Health Organization, 2008). This article presents a study that aimed to increase understanding of the context of the reform and barriers to it in two adjacent political districts that are running the programme's pilot phase. The goal of this work is to provide a framework for systematically addressing barriers when scaling up mental health services in Niger (Saraceno et al, 2007; Eaton et al, 2011).

\section{Setting}

Niger, in West Africa, ranks near the bottom of the Human Development Index, which is a combined measure of life expectancy, education levels and standard of living (United Nations Development Programme, 2009). Over $80 \%$ of the country is in the Sahara Desert, which presents unique challenges to healthcare provision. The treatment gap for severe mental disorders is estimated to be over $90 \%$, partly because mental health services and senior professionals are located in central tertiary institutions - primarily at the University Hospital in Niamey, the country's capital (Wang et al, 2007). In the last decade, initial efforts at decentralisation have been made, with 15 psychiatric nurses posted outside of the capital, mostly at regional or district hospitals

Although non-governmental organisations (NGOs) are an important provider of services in Niger, few work in mental health. One exception is the organisation $\mathrm{CBM} / \mathrm{ProDiB}$, which uses a community-based rehabilitation (CBR) model with field workers supported by outreach visits from a psychiatric nurse. In 2010, this organisation partnered with the National Mental Health Programme to develop an implementation strategy for scaling up community-based services at the national level.

To prepare for implementation of the national policy, two districts, Dosso and Dogondoutchi, were chosen for a pilot programme. They are located in the south-western corner of Niger, where most of the population lives, $139 \mathrm{~km}$ and $273 \mathrm{~km}$ east of the capital city of Niamey, respectively. In both regions, subsistence farming involves more than $80 \%$ of the adult population (Système Nationale d'Information Sanitaire, 2007). Table 1 presents health and demographic statistics for the two districts of Niger that are the focus of this study. 
Table 1

Health statistics and resources in Niger

\begin{tabular}{|c|c|c|c|}
\hline & Nationwide & Dogondoutchi District & Dosso District \\
\hline Population & $15,306,250^{a}$ & 622,957 (estimated) & 446,028 (estimated) \\
\hline Life expectancy at birth & 53.8 years $(54.3 \text { female, } 53.4 \text { male })^{b}$ & - & - \\
\hline Adult literacy rate & $28.7 \%(15.1 \% \text { female, } 42.9 \% \text { male })^{c}$ & - & - \\
\hline Fertility rate (births per woman) & 7.1 (highest rate in the world) $^{b}$ & - & - \\
\hline Number of public hospitals, all types & 3 national, 6 regional, 30 district & 1 district & 1 regional \\
\hline $\begin{array}{l}\text { Numbers of integrated health centres (IHCs) } \\
\text { type } 1 \text { IHCs } \\
\text { type } 2 \text { IHCs }\end{array}$ & $\begin{array}{l}482 \\
151\end{array}$ & $\begin{array}{r}15 \\
5\end{array}$ & $\begin{array}{r}19 \\
4\end{array}$ \\
\hline Number of local health clinics (LHCs) & 1938 & 98 & 82 \\
\hline
\end{tabular}

aSource: United Nations Development Programme, Human Development Report, 2009

bSource: United Nations Population Division, World Population Prospects, 2009.

'Source: United National Educational, Scientific, and Cultural Organization (UNESCO) Institute for Statistics, 2005.

All health facility resource data from Système Nationale d'Information Sanitaire, Niger, 2007.

\section{Method}

Semi-structured interviews were conducted with primary care providers at 25 health centres in the two districts. Respondents were asked about their knowledge and attitudes, perceived wants and needs and available resources in the area of mental health services. In addition, study staff met key informants at the district, regional and national levels and accessed databases and hospital records for demographic and epidemiological information. Unpublished statistical data, including some of those presented in Table 1, were also collected from the office of the National System for Health Statistics (Système Nationale d'Information Sanitaire, SNIS) in 2007.

Multiple validated instruments were reviewed, including the World Health Organization Assessment Instrument for Mental Health Systems (WHO-AIMS, Version 2.2), the World Psychiatric Association's Discrimination and Stigma Scale Version II (DISC II), the Mental Health Knowledge Scale (MAKS3), the Reported and Intended Behaviour Scale 4 (RIBS 4) and questionnaires approved and used for advanced academic dissertations (World Psychiatric Association, 2001; Badagé, 2007; Thornicroft et al, 2009). However, none of these fully matched the intended aims of our study, so we developed a locally specific survey using relevant portions of these instruments. Two psychiatric nurses were consulted for modifications before the survey was finalised.

This article presents responses from two sec tions of the survey:

- priorities for improvement - respondents were asked to rank-order a list of priorities for improving mental health services at their respective facilities

- barriers to care - respondents were asked to discuss barriers to accessing psychiatric care for community members.

\section{Results}

In total, the head nurses at 14 integrated health centres (IHCs) and community health workers at

\section{Table 2}

Priorities for improving mental health services in Niger, as ranked by 25 interviewees at primary care clinics

\begin{tabular}{|l|l|}
\hline Priority & $\begin{array}{l}\text { Proportion (number) } \\
\text { of interviewees rank- } \\
\text { ing as top priority }\end{array}$ \\
\hline $\begin{array}{l}\text { Training staff in diagnosis, treatment } \\
\text { and follow-up for psychiatric illness }\end{array}$ & $52 \%(13)$ \\
\hline $\begin{array}{l}\text { Raising awareness and providing } \\
\text { workshops for the community and } \\
\text { patients' families about mental illness }\end{array}$ & $28 \%(7)$ \\
\hline $\begin{array}{l}\text { Building relations with and providing } \\
\text { training to traditional healers }\end{array}$ & $12 \%(3)$ \\
\hline Access to medication & $8 \%(2)$ \\
\hline
\end{tabular}

11 local health clinics (LHCs) were interviewed. In addition, five key informants were interviewed: the psychiatric nurse at the Dosso regional hospital; the regional manager for public health; the medical directors of both district departments of health; and a Dosso-based community field worker.

Priorities for improvement fell into four main categories, summarised in Table 2: training staff in diagnosis, treatment and follow-up; raising awareness about mental illness; building relations with traditional healers; and access to medication.

\section{Staff training}

Community health workers at the LHCs undergo 6 months of training, with no formal entry qualifications. They do not have authority to prescribe medications, although they do distribute anti-malarial drugs, contraceptives, vitamins and antibiotics.

The heads of IHCs are state-licensed nurses who have attended 3 years of nursing school and can prescribe medications. In 2003 a psychiatric nursing school opened in Niamey and it is now graduating seven or eight students every 2 years. Before this, students most often went to Burkina Faso (Eaton et al, 2009). Only four of the 25 providers interviewed had received any training in mental health beyond what they had learned during the fundamental 20-hour course offered in general nursing or community health. One 
respondent at an IHC said he had the authority to order and prescribe psychotropic medications, but since he had not been trained on proper dosage or monitoring for mental illness, he did not feel comfortable issuing prescriptions.

Training for psychiatrists most commonly takes place in Benin, Senegal, Morocco or France, as Niger does not have a training programme. At the time of study there were four psychiatrists working in Niger, all based in the capital.

The majority of clients at LHCs and IHCs were immediately referred to a tertiary care centre because the healthcare workers felt they did not have the required medical expertise. Patients in both districts were usually sent to the regional hospital of Dosso, which has a department of psychiatry and a psychiatric nurse. There was little to no follow-up done at a community level after the patient was discharged from the hospital. Community-based staff said they did not receive the counter-referrals from the hospital with intake and discharge information, and were not trained or resourced to provide follow-up care.

One of the unfortunate side-effects of limited community-based expertise is that, according to one respondent, families avoid seeking help at the local clinic because they expect to be referred to the hospital and cannot afford the transportation costs; as a result, these families do not receive any care.

\section{Raising awareness and building relations with traditional healers}

According to the respondents, the majority of community members believe that supernatural forces lead to mental illness and therefore visit traditional healers, who use methods such as herbal remedies, incantations and animal sacrifice. Twelve of the 25 provider interviewees reported having a working relationship with the healers, and 8 of these 12 said that healers referred patients to them when traditional treatments failed. However, since traditional practices can be expensive (for example payment with a goat), affording modern medical services is subsequently more difficult. One respondent emphasised the importance of educating families and patients, as parents often do not seek medical care for children with mental illness. Another respondent recommended raising community awareness by presenting pictures or skits of people with mental illness, in treatment and 'healed'.

\section{Access to medication}

In theory, all of the psychotropic medications on the World Health Organization's Bamako Initiative list of essential generic drugs should be available in Niger, except amitriptyline and trifluoperazine. However, access to these drugs is extremely limited in reality. Phenobarbital, for example, should be available (for approximately US $\$ 2$ per month) but few pharmacies or IHCs consistently carried the drug. Seven respondents provided phenobarbital at their facilities, at times contingent on receiving free supplies from NGOs or UNICEF. Diazepam is widely available and is primarily used for convulsions associated with malaria, but is frequently overprescribed for non-specified behavioural problems.

The absence of a structured drug delivery system hinders medication adherence. Most patients must go to the nearest IHC or hospital for medication, and transportation costs, usually with a carer, are unaffordable (typically US $\$ 20$ or more), largely due to the long distances. The average worker makes less than US $\$ 1$ a day and cannot leave the fields during planting season (June-August), which renders repeat prescriptions in particular economically and logistically unfeasible, and so many patients abandon treatment. A few nurses use their motorbikes to pick up medication for their patients, creating an ad hoc drug delivery system.

Local health workers expressed reluctance to conduct home and community visits, primarily for economic reasons. Government employees expect a daily allowance for 'out of office' duties. Health programmes in malaria and HIV/AIDS provide these per diems, which, according to the medical director at the Dogondoutchi health department, are up to US $\$ 10$ for a community health worker, US $\$ 20$ for a nurse and US $\$ 50$ for a psychiatric nurse. This sets a high, often impossible, cost for the national government and local NGOs, and acts as a major barrier to decentralising and scaling up services (Vian et al, 2013).

\section{Discussion}

The expressed need to improve local access to mental healthcare and the tendency for providers to automatically refer to the hospital confirm the relevance of current shifts towards decentralised services. Since $90 \%$ of the population live in rural areas, providing reliable medication in primary care is essential for those requiring long-term treatment, as is often the case with psychiatric illness. Community-based assessment and treatment are desirable but cannot become a reality until practitioners are adequately trained and home visits are viewed as routine work, and not requiring additional pay.

Our findings also support previous studies that found that the community's understanding of the aetiology of psychiatric disorders leads people to seek treatment from a traditional healer rather than modern healthcare providers (Maiga et al, 2008). Sensitisation and awareness-raising, in conjunction with structured collaborations with traditional healers, may help patients receive appropriate care earlier in the course of disease.

\section{Conclusion}

Niger has an opportunity to address its huge burden of unmet mental health needs in a context of great poverty. The process of doing this must not only address internationally recognised challenges to scaling up (Saraceno et al, 2007) but also take into account locally identified barriers and resources. 


\section{References}

Badagé, S. (2007) Les Besoins en Soins de Santé Mentale de la Population de la Région de Dosso République du Niger (Mémoire Attaché de Santé) [The Need for Mental Healthcare of the Population of the Region of Dosso, Republic of Niger (Memoire from the Health Secretary)]. Ecole Nationale de Santé Publique.

Eaton, J., Maiga, D. D. \& Pate, S. (2009) Mental health services in the Republic of Niger. International Psychiatry, 6, 63-64.

Eaton, J., McCay, L., Semrau, M., et al (2011) Scale up of services for mental health in low-income and middle-income countries. Lancet, 378, 1592-1603.

Maiga, O. D., Abdou, A. \& Modibo, M. (2008) Contribution à l'évaluation des besoins en santé mentale. [Contribution to the assessment of mental health needs.] Médecine d'Afrique Noire, no. 5503, 169-175.

Saraceno, B., van Ommeren, M., Batniji, R., et al (2007) Barriers to improvement of mental health services in low-income and middleincome countries. Lancet, 370, 1164-1174.

Système Nationale d'Information Sanitaire (2007) Annuaire des Statistiques Sanitaires au Niger. [Annual Report of Health Statistics in Niger.] SNIS.
Thornicroft, G., Brohan, E., Rose, D., et al, for the INDIGO Study Group (2009) Global pattern of experienced and anticipated discrimination against people with schizophrenia: a cross-sectional survey. Lancet, 373, 408-415.

United Nations Development Programme (2009) Overcoming barriers: Human mobility and development. See http://hdr.undp. org/sites/default/files/reports/269/hdr_2009_en_complete.pdf (accessed December 2013).

Vian, T., Miller, C., Themba, Z., et al (2013) Perceptions of per diems in the health sector: evidence and implications. Health Policy and Planning, 28, 237-246.

Wang, P. S., Aguilar-Gaxiola, S., Alonso, J., et al (2007) Use of mental health services for anxiety, mood, and substance disorders in 17 countries in the WHO world mental health surveys. Lancet, 370 , 841-850.

World Health Organization (2008) mhGAP: Mental Health Gap Action Programme: Scaling Up Care for Mental, Neurological, and Substance Use Disorders. WHO.

World Health Organization (2011) Atlas. Country Profile of Mental Health Resources. WHO.

World Psychiatric Association (2001) The WPA Global

Programme to Reduce the Stigma and Discrimination Because of Schizophrenia - An Interim Report 2001. WPA.

\title{
RESEARCH PAPER \\ Evaluation of undergraduate psychiatry teaching in Malawi
}

\author{
Amy E. Lindsay ${ }^{1}$ and Stephen Byers ${ }^{2}$
}

${ }^{1}$ Consultant Psychiatrist, St John's Hospital, NHS Lothian, UK, email amylindsay@nhs.net

${ }^{2}$ Consultant Psychiatrist, NHS Greater Glasgow and Clyde, UK

The contribution of Felix Kauye, Consultant Psychiatrist, is gratefully acknowledged.
In Malawi, mental health services account for only $2 \%$ of the health budget; there are just 4.5 full-time psychiatrists and 433 psychiatric beds. The Scotland Malawi Mental Health Education Project (SMMHEP) aims to provide sustainable support for psychiatric training for healthcare professionals and has increased the number of psychiatrists in the country. There has been a recent change in the educational programme in order to maximise clinical exposure and experience, particularly with the care of in-patients. The new programme has had a positive effect on students' attitudes towards psychiatry and their consideration of psychiatry as a career. This paper supports the ongoing work SMMHEP does in developing psychiatric services through education.

Malawi is a low-income country in sub-Saharan Africa. Life expectancy is 54 years and the literacy rate is $75.5 \%$ for men and $48.7 \%$ for women.

Malawi has an estimated population of 15.91 million and an area of approximately $118000 \mathrm{~km}^{2}$. It is split into 28 health districts, most of which have a district hospital. The Malawi College of Medicine in Blantyre opened in 1991 and is the only medical school. The country has one government psychiatrist, two psychiatrists employed by the College of Medicine, one psychiatrist from the American Peace Corps and one psychiatrist employed part time by the Scotland Malawi Mental Health Education Project (SMMHEP). The national psychiatric hospital, with 333 beds, is located in the former colonial administrative capital city, Zomba. Two 50-bed units are staffed by nurses and clinical officers, giving a total of 433 psychiatric beds for the country (Kauye, 2008). Two per cent of the country's health budget is spent on mental health (World Health Organization, 2005).

The neuropsychiatric burden for Malawi is 2497.43 disability-adjusted life years (DALYs) per 100000 and the suicide rate is 7.03 per 100000 , compared with medians for all countries of 2964 DALYs and 6.55 suicides per 100000 (Jacob et al, 2007). The 2002 international 'burden of disease' data from the World Health Organization suggested that unipolar depression is the fourth leading cause of disability in Malawi, following HIV/AIDS, cataracts and malaria (Bowie, 2006).

A recurrent suggestion to address such treatment gaps and lack of psychiatric training is that the UK could provide visiting psychiatrists to support educational programmes in other countries (Hanlon et al, 2006; Kulhara \& Avasthi, 2007; Mullick, 2007).

The aim of SMMHEP is to provide sustainable support for psychiatric training at the Malawi 